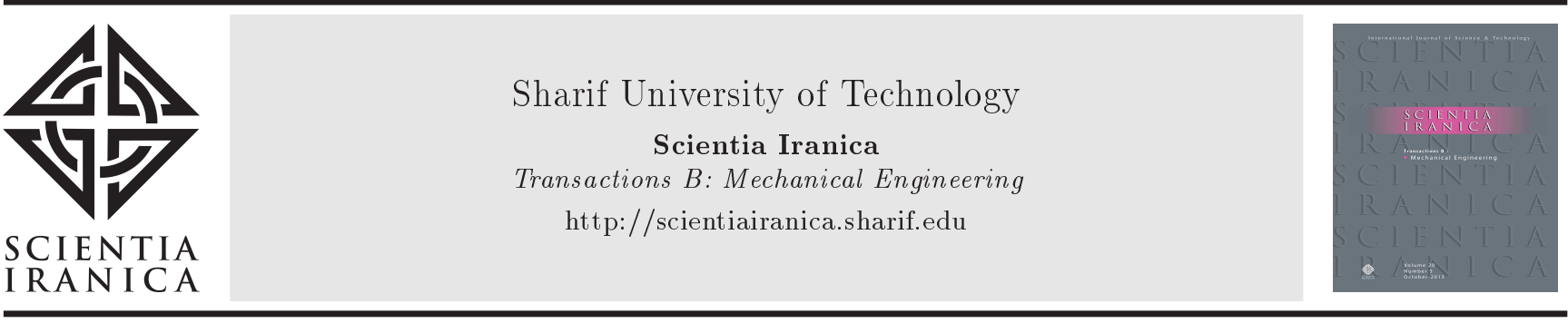

\title{
Assessment of optimum slurry pipe design for minimum erosion
}

\author{
V. Kannojiya ${ }^{a, *}$ and S. Kumar ${ }^{b}$ \\ a. Mechanical and Industrial Engineering Department, Indian Institute of Technology, Roorkee, 247667, India. \\ b. Mechanical Engineering Department, Thapar University, Patiala, 147001 , India.
}

Received 24 October 2018; received in revised form 20 May 2019; accepted 7 September 2019

\section{KEYWORDS}

Slurry erosion;

Multi-phase flow;

CFD modeling;

Bottom ash;

Pipeline.

\begin{abstract}
Particulate erosion in the slurry handling unit of a thermal power plant is a major concern. Pipe bends are the most erosion-affected elements of a pipeline unit; hence, adopting a cost-effective method to reduce pipeline erosion is a necessity. This work aims to propose an optimal pipe bend design to minimize particulate erosion by analyzing the erosive wear of geometrically different pipe bends for bottom ash slurry flow using computational fluid dynamics code, i.e., FLUENT. A three-dimensional simulation study of erosive wear was carried out by applying Euler-Lagrange modeling along with the standard $k-\varepsilon$ turbulence model to solve the complex multi-phase flow. Pipe bends with different bending angles $\left(30^{\circ}, 45^{\circ}, 60^{\circ}\right.$, and $\left.90^{\circ}\right)$, diameters (50 to $\left.250 \mathrm{~mm}\right)$, and bending ratios $(r / D=1$ to 2.5$)$ were evaluated in different flow conditions. The wear location shifted to the upper section of the bend and its magnitude was significantly reduced with an increase in pipe diameter and bending angle. The dynamics of multiphase slurry through different bends was analyzed to understand the complex wear phenomenon. The simulation result showed good agreement with the previous published findings. Finally, the least erosionaffected pipe bend design was suggested for the slurry transport unit.
\end{abstract}

(C) 2020 Sharif University of Technology. All rights reserved.

\section{Introduction}

Some machinery components used in power generation unit, gas extraction division, oil and chemical industries, etc. suffer considerable erosive wear due to multiple impingements of solid particles. Erosive wear of such components can cause significant material loss and low productivity [1]. At Indian thermal power plants, approximately 207 metric tons of ash is produced from 594 metric tons of feeded coal to

*. Corresponding author. Tel.: +91:8725953816 E-mail addresses: vikas.passion.singh@gmail.com (V. Kannojiya); satish.kumar@thapar.edu (S. Kumar)

doi: $10.24200 /$ sci. 2019.52073 .2519 generate 96.74 gigawatts. Ash possesses highly abrasive characteristics. Out of total ash, an approximate $20 \%$ share is bottom ash [2]. The generated ash is disposed to ash well/ponds/storage lagoon through the pipelines or tubes in the form of ash-water slurry [3]. The solid abrasive particles present in the slurry collide with the pipe wall and degrade/remove considerable material. The pipe with deteriorated surface has a higher probability of failure [4-5]. Erosive wear is a complex phenomenon to understand as it depends on several influencing parameters like the attribute of abrasive/erodent, target material, shape of conveyer, and flow characteristics [6-10]. The involvement of various parameters makes it very difficult to experimentally solve the whole phenomenon of erosive wear.

The gradual development of computational tech- 
niques including Computational Fluid Dynamics (CFD) offers a convinient method to analyze such a phenomenon without difficult experimentation. CFD simulations provide a cost-effective approach in order to grasp the complicated fluid dynamics and are universally accepted by investigators to solve complex flow problems [11-12].

The geometrical configuration of slurry pipe affects the erosion behavior; therefore, a careful understanding of it is a must. Zhang et al. [13] stressed the significant effect of geometrical aspects of slurry pipe on erosive wear patterns. They examined the particle deposition on different curvature bends and showed the strong dependence of flow pattern on the bend curvature ratio and Reynolds's number. Zahedi et al. [14] simulated the particulate erosion of bends with a $90^{\circ}$ degree and long radius. They discussed the effect of pipe diameter variation on the erosive wear characteristics at different flow velocities and particle sizes. Peng and Cao [15] performed a computational study on the pipe with a different orientation to analyze the erosive wear using the two-way coupled Euler-Lagrange model. The CFD-based study showed that the bending radius-to-pipe diameter ratio $(r / D)$ could influence the particle interaction with the pipe wall. The literature shows that slurry erosion can be effectively predicted by using CFD tools. However, these studies are mainly focused on the investigation of erosive wear caused by the sand slurry flow.

Erosive wear due to the complex slurry flow of bottom ash and water through the slurry pipe has been reported by a few studies. The erosion risk of the components of thermal power plants has been pointed out by some researchers [16-18]. Goosen and Malgas [19] conducted an experimental analysis of wear of the bottom ash disposal pipeline. They investigated a slurry pipe loop for the flow of water-bottom ash slurry. The effect of various operating parameters on the wear rate of the pipeline was investigated. The possibility of wear reduction by adding fly ash to the slurry was also discussed. Das et al. [20] proposed a numerical model to predict the rate of erosive wear of boiler components due to multiple impingements of fly ash particles. They examined the wear rate at different impingement angles, various temperature conditions, and different flow velocities. The peak erosion rate was observed at a impingement angle of $30^{\circ}$. Singh et al. [21] experimentally analyzed the erosive wear of a mild steel and stainless steel 304 test specimen by bottom ash slurry. Their findings showed the variation of erosion wear characteristics with bottom ash concentration and slurry velocity. They reported stainless steel 304 to be more erosion-resistant. Singh et al. [22] modeled erosive wear of bottom ash slurry flow through a $90^{\circ}$ pipe bend. The CFD-based study was used to analyze the erosive wear characteristics at different slurry concentrations and flow velocities. Recently, Kannojiya et al. [23] examined the erosive wear characteristics of a straight pipe caused by the flow of bottom ash-water slurry. They reported the effect of erodent size and slurry velocity on the erosion wear characteristics.

Literature on erosion behavior due to impingement of bottom ash particles on the wall of the slurry pipe is scarce. Moreover, the effect of geometrical pipeline aspects on the erosion characteristics has not been discussed in such studies. So far, no study has presented an optimal design of ash handling pipelines to keep erosion minimum. Therefore, in this work, erosive wear of geometrically different pipe bends induced by bottom ash slurry is initiated to achieve the least erosion-affected pipeline system. The computational simulations were carried out using DPM (Discrete Phase Model) in CFD code FLUENT with a standard $k-\varepsilon$ turbulence modeling scheme. This study attempts to propose an optimum pipeline configuration that can effectively transport the solid-liquid multiphase slurry.

\section{Mathematical model}

In the present study, the Euler-Lagrange two-phase model was applied. The liquid phase was treated as a continuous phase and its solution was obtained through the time-averaged $\mathrm{N}-\mathrm{S}$ equation, while the secondary phase was solved using Lagrange tracking. The discrete solid phase applied a force to the continuous phase, which caused turbulence of flowing media. The flow turbulence was solved by applying the standard $k-\varepsilon$ turbulence model.

\subsection{Flow modeling}

The following governing equations were employed to solve the multiphase flow problem of the solid-liquid:

Continuity equation:

$$
\frac{\partial \rho}{\partial t}+\nabla \cdot(\rho \vec{V})=0
$$

Momentum equation [15]:

$$
\begin{aligned}
\frac{\partial \rho \vec{V}}{\partial t}+\nabla \cdot(\rho \vec{V} \vec{V})=-\nabla P+\nabla \\
\cdot\left[\mu\left\{\left(\nabla \vec{V}+\nabla \vec{V}^{T}\right)-\frac{2}{3} \nabla \vec{V} I\right\}\right]+\overrightarrow{\rho g}+\overrightarrow{S_{m}} .
\end{aligned}
$$

Symbols $\rho$ and $\nabla$ denote the fluid density and partial derivatives with respect to all directions, respectively. $\vec{V}$ is the instantaneous velocity vector, $P$ the pressure, $\overrightarrow{\rho g}$ the body force, $I$ the unit tensor, and $\overrightarrow{S_{m}}$ the added momentum due to the solid phase. 


\subsection{Turbulence model}

The turbulence of the flow was tracked by employing the standard $k-\varepsilon$ turbulence model. The turbulent kinetic energy $(k)$ transportation equation is given below [15]:

$$
\begin{aligned}
\frac{\partial \rho k}{\partial t} & +\frac{\partial\left(\rho V_{i} k\right)}{\partial x_{i}}=\frac{\partial}{\partial x_{j}}\left[\left(\mu+\frac{\mu_{t}}{\sigma_{k}}\right) \frac{\partial k}{\partial x_{j}}\right] \\
& +G_{k}-\rho \varepsilon+S_{k} .
\end{aligned}
$$

The dissipation of turbulent kinetic energy $(\varepsilon)$ can be written as follows:

$$
\begin{aligned}
\frac{\partial \rho \varepsilon}{\partial t} & +\frac{\partial\left(\rho V_{i} \varepsilon\right)}{\partial x_{i}}=\frac{\partial}{\partial x_{j}}\left[\left(\mu+\frac{\mu_{t}}{\sigma_{\varepsilon}}\right) \frac{\partial \varepsilon}{\partial x_{j}}\right] \\
& +\frac{\varepsilon}{k}\left(C_{\varepsilon 1} G_{k}-\rho \varepsilon C_{\varepsilon 2}\right)+S_{\varepsilon} .
\end{aligned}
$$

Here, $G_{k}$ represents the turbulent kinetic energy generation due to mean velocity gradients; $C_{\varepsilon 1}$ and $C_{\varepsilon 2}$ are constants; $V_{i}$ represents the velocity component in the direction $i ; x_{i}$ and $x_{j}$ are the spatial coordinates; $\sigma_{k}$ and $\sigma_{\varepsilon}$ are the turbulent Prandtl numbers for $k$ and $\varepsilon$, respectively; and $S_{\varepsilon}$ and $S_{k}$ are the source terms.

\subsection{Particle tracking model}

Particle trajectories were predicted by integrating the force balance equation of particle. In the force balance equation, the particle inertia was equal to the forces applied to the particles and could be written as follows [24]:

$$
\frac{d V_{P}}{d t}=F_{D}\left(V-V_{P}\right)+\frac{g\left(\rho_{P}-\rho\right)}{\rho_{P}}+F,
$$

where $F$ represents the force per unit mass and $F_{D}$ is the drag force that can be expressed below:

$$
F_{D}=\frac{18 \mu}{\rho_{P} d_{p}^{2}} \frac{C_{D} \operatorname{Re}}{24} .
$$

Here, the symbols $V, V_{p}, \mu, \rho_{P}$, and $d_{p}$ are the fluid phase velocity, particle velocity, fluid molecular viscosity, particle density, and particle diameter, respectively. The term $C_{D}$ is the drag coefficient that can be written as follows:

$$
C_{D}=a_{1}+\frac{a_{2}}{\operatorname{Re}}+\frac{\alpha_{3}}{\operatorname{Re}^{2}},
$$

where $a_{1}, a_{2}$, and $\alpha_{3}$ are the coefficients given by Morsi and Alexander [25].

The term Re is the particle Reynolds number that can be written as follows:

$$
\operatorname{Re}=\frac{\left(\rho d_{p}\left|V-V_{P}\right|\right)}{\mu} .
$$

Stochastic tracking was applied to observe the particle randomness occurring due to flow turbulence. The dispersion effect of the particle caused by the turbulence of flow can be predicted by using fluctuating component of fluid velocity as follows:

$$
V=V^{\prime}+V(t)
$$

In the stochastic approach, particle paths are predicted by integrating the above equation for every single particle.

\subsection{Particulate erosion rates}

Edwards [26] proposed a numerical model to predict pipeline erosive wear due to particulate impingement, which is accepted by many researchers [22,27-30]. The erosive rate $(E)$ can be expressed as the ratio of mass extracted/removed from a target surface to the summation of the mass of all of the impacting particles. The model takes into account the impacting particle flow rate $\left(m_{p}\right)$, the surface area of the impacted wall boundary cell $\left(A_{f}\right)$, and the impact angle function $(f(a))$. The governing equation of this model can be written as follows:

$$
\operatorname{Erosion}(E)=\sum_{p=1}^{N \text { particles }} \frac{\left(m_{p} c\left(d_{p}\right)\right) f(a) v^{b(v)}}{A_{f}}
$$

The terms $v, c, b$ denote the relative velocity between particles, particle diameter function, and velocity exponent, respectively. $A_{f}$ is the cell face area along the wall and $a$ represents impact angle made by particle with the wall face. Impact angle function, denoted by $f(a)$, can be defined by piece-wise linear profile, whose details are mentioned in Table 1 . The values of diameter function and velocity exponent are $1.8 e^{-09}$ and 2.6, respectively [31].

\section{CFD simulation}

\subsection{Flow domain}

The pipeline domain was modeled by using ANSYS Design Modeler. The length of both straight sections of the mild steel pipe bend was taken as $1 \mathrm{~m}$ for the smaller diameter pipe ( 50 and $100 \mathrm{~mm}$ ) and $2 \mathrm{~m}$ for the larger diameter pipe (150 to $250 \mathrm{~mm}$ ). Figure 1 shows

Table 1. Value of impact angle function at different points of bend.

\begin{tabular}{ccc}
\hline Points & Angle & Values \\
\hline 1 & 0 & 0 \\
2 & 20 & 0.8 \\
3 & 30 & 1 \\
4 & 45 & 0.5 \\
5 & 90 & 0.4 \\
\hline
\end{tabular}




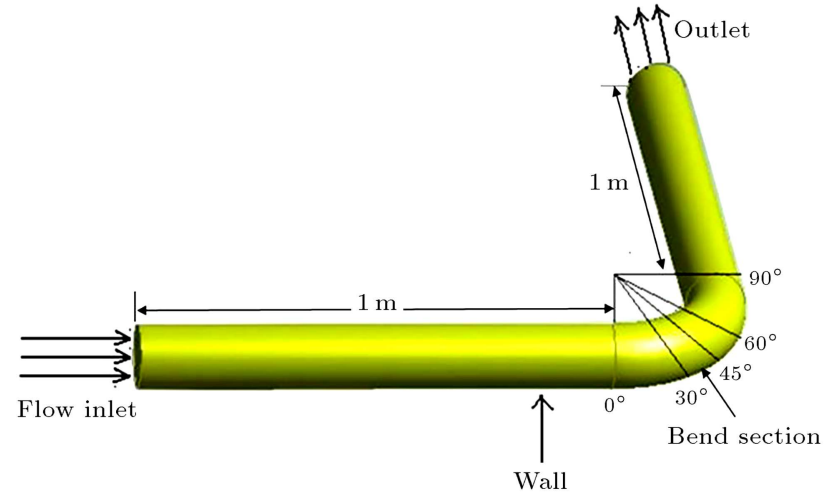

(a) Domain description

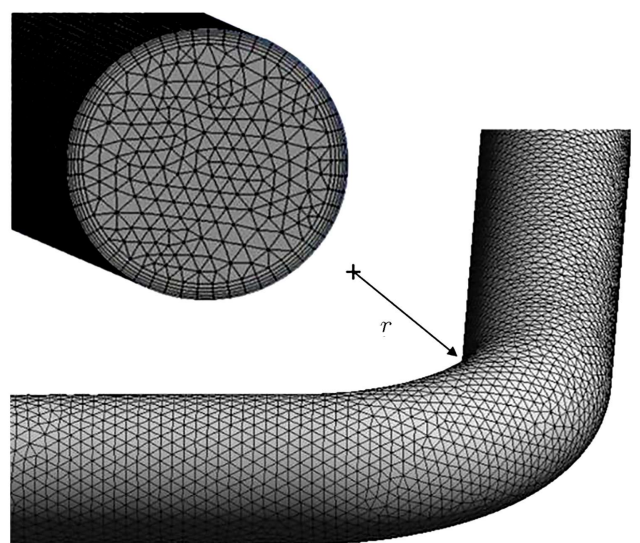

(b) Domain discretization

Figure 1. Domain description and discretization.

a detailed view of the flow domain. The analysis of erosive wear of different versions of the slurry pipeline was carried out by considering various pipe bends having different diameters (50 to $250 \mathrm{~mm}$ ), radiusto-diameters ratios ( 1 to 2.5 ), and different bending angles $\left(30^{\circ}, 45^{\circ}, 60^{\circ}\right.$ and $\left.90^{\circ}\right)$. The multiphase slurry contains $10 \%$ (by weight) of bottom ash and the rest is water; the ash particles $150 \mu \mathrm{m}$ in size were injected to the inlet face of the pipeline. The study was carried out at different flow velocities ranging from 2 to $8 \mathrm{~m} / \mathrm{s}$. The properties of the solid-liquid slurry are discussed in Table 2. Simulations were carried out at Windows-based Intel Xenon E5-1620 V3 machine with $3.5 \mathrm{GHz}$ processor and $16 \mathrm{~GB}$ RAM. The convergence was achieved when residuals of governing equations dropped below $10^{-6}$.

To precisely capture the multi-phase flow phenomenon, the flow domain was divided into tetrahedral elements after suitable mesh sensitivity analysis. Figure 2 shows variations in the erosion rate for the $100 \mathrm{~mm}$ diameter pipe with number of grid elements at a flow velocity of $4 \mathrm{~m} / \mathrm{s}$. It can be observed that for the coarser grid (elements $<1.65 \times 10^{6}$ ), the variation in erosion rate between two consecutive refinements was higher, whereas for the finer mesh (elements $>1.80 \times 10^{6}$ ), no considerable variation in simulation outcomes was detected. Therefore, the computational domain was discretized into $18,63,534$ tetrahedral elements. A better understanding of the interaction between the solid particles and the pipe

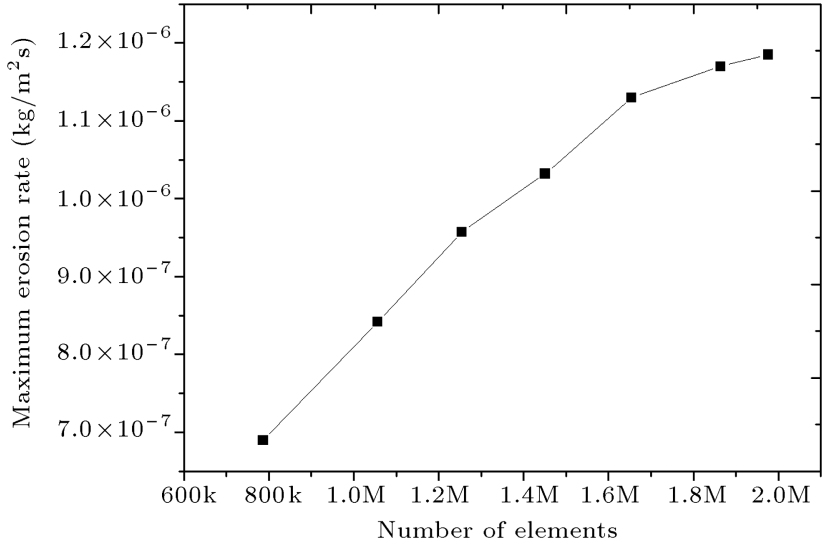

Figure 2. Variation of erosion rate with number of elements.

wall is very vital for accurately monitoring the erosive wear; thus, five layers of inflation were introduced to the mesh, as represented in Figure 1.

\subsection{Boundary conditions}

The computational domain has a single velocity inlet to allow the slurry flow, a single pressure outlet subjected to atmospheric pressure. The spherical ash particles were injected from the inlet section. The flow velocity was $2 \mathrm{~m} / \mathrm{s}$ which later varied from $2 \mathrm{~m} / \mathrm{s}$ to $8 \mathrm{~m} / \mathrm{s}$ for further simulations. No-slip condition was applied to the wall surface with a roughness constant of $0.5 \mathrm{~mm}$. The boundary condition between solid particulate and the wall was set to 'reflect'. Pressure and velocity

Table 2. Properties of multiphase flow.

\begin{tabular}{cccc}
\hline Properties & Fluid (water) & Solid (bottom ash) & Target (mild steel) \\
\hline Density $\left(\mathrm{kg} / \mathrm{m}^{3}\right)$ & 1000 & 2200 & 7850 \\
Particle size $(\mu \mathrm{m})$ & - & 150 & - \\
\hline
\end{tabular}


were coupled using SIMPLE algorithm. Standard $k-\varepsilon$ turbulence modeling scheme with standard wall functions was applied to solve the turbulence of the flow. The convergence criterion was set to $10^{-6}$.

\subsection{Validation}

In this section, the present numerical framework was verified with the published findings of Singh et al. [22] and Shamshirband et al. [32] (as mentioned in Case 1 and Case 2, receptively):

Case 1: The present simulation framework was verified by comparing the simulation outcomes with the numerical study of Singh et al. [22]. They [22] studied the erosive wear behavior of the bottom ash slurry flow through a $90^{\circ}$ pipe bend characterized by $100 \mathrm{~mm}$ diameter in different flow conditions. The numerical study was carried out by using CFDFLUENT for ash slurry having different bottom ash concentrations ranging from 2.5 to $10 \%$ by volume. One case of Singh et al. [22] (effect of slurry concentration on the erosion) was considered and simulated under the same boundary and flow conditions. According to Figure 3, the numerical prediction using the present simulation framework showed better agreement with results of Singh et al. [22] and the variation was within $5 \%$.

Case 2: The CFD framework was also verified with the published findings of Shamshirband et al. [32]. They simulated erosive wear of a $90^{\circ}$ pipe bend for the flow of sand water slurry using DPM model of ANSYS-CFD with a standard $k-\varepsilon$ modeling scheme. They analyzed the effect of sand particulate size variations $(10 \mathrm{~nm}$ to $100 \mu \mathrm{m})$ at a different flow velocity ( 5 to $20 \mathrm{~m} / \mathrm{s}$ ) on the erosive wear characteristics. Few cases of the particle size variations were simulated in the same conditions, the results of which are presented in Figure 4. It was found that the

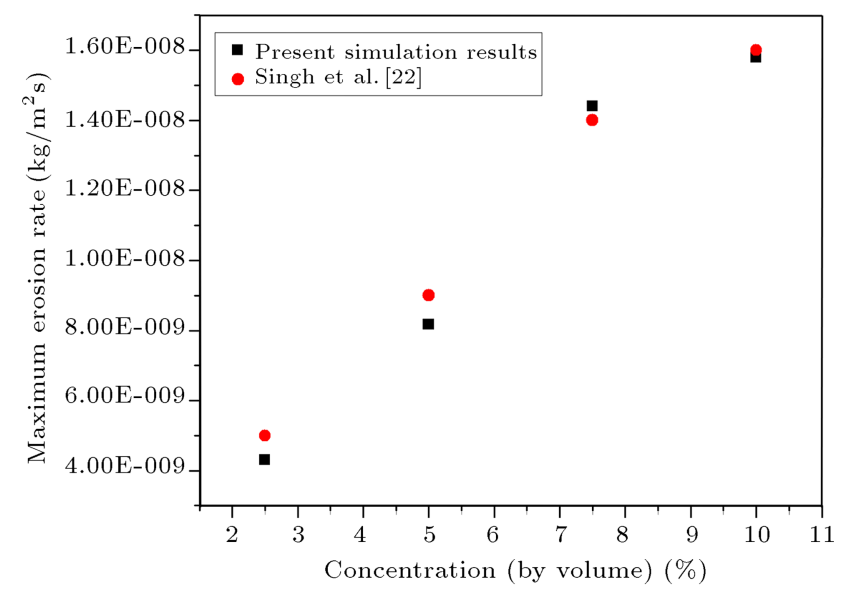

Figure 3. Validation of present model with Singh et al. [22]. present simulations underpredicted the erosion and its variation was lower than $8 \%$.

\section{Results and discussion}

\subsection{Selection of optimum bending angle}

The effect of pipe bending angle on the erosive wear rate was investigated to select an optimum bending angle that could attenuate the erosion damage. Several pipe bends having different bending angles $\left(30^{\circ}, 45^{\circ}\right.$, $60^{\circ}$, and $90^{\circ}$ ) were simulated for $10 \%$ ash concentration at different flow velocities, and their corresponding erosion wear characteristics were analyzed to determine the least erosion-affected pipe bend. The magnitude of erosion of several pipe bends at different flow velocities is shown in Figure 5. The maximum erosion rate $\left(7.5 \times 10^{-5} \mathrm{~kg} / \mathrm{m}^{2} \mathrm{~s}\right)$ was detected for the $30^{\circ}$ bend, whereas the lowest wear rate $\left(1.6 \times 10^{-5} \mathrm{~kg} / \mathrm{m}^{2} \mathrm{~s}\right.$, approximately 4 times low) was observed for the $90^{\circ}$ bend (at a velocity of $8 \mathrm{~m} / \mathrm{s}$ ). It was also determined that under similar operating conditions, erosion rate

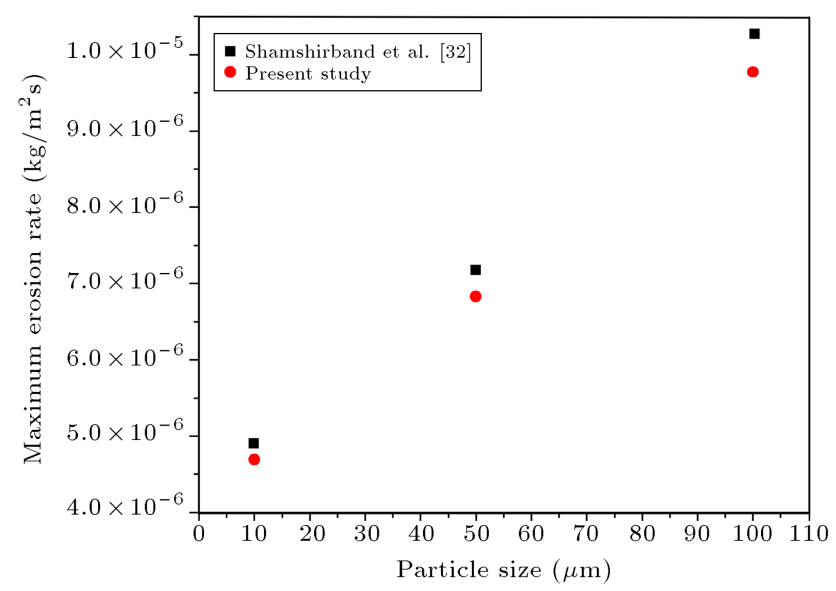

Figure 4. Validation of present model with Shamshirband et al. [32].

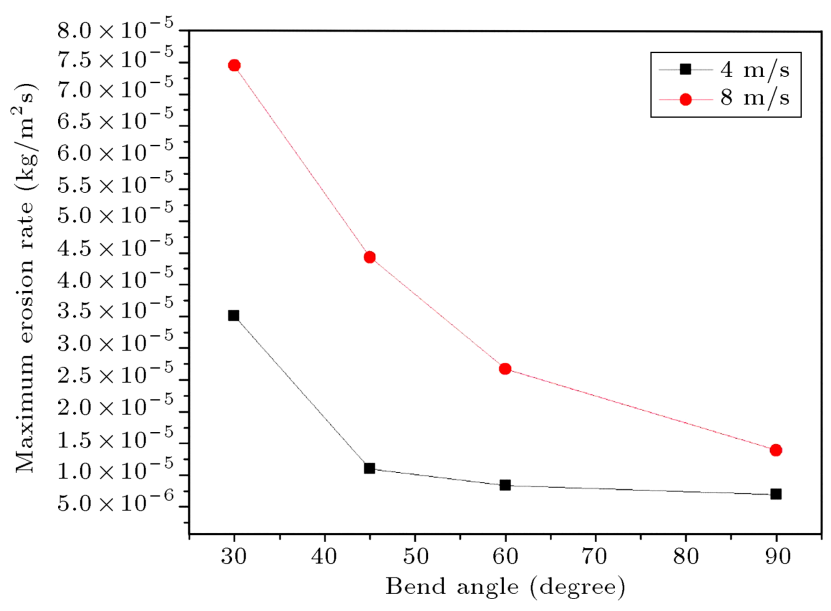

Figure 5. Effect of bending angle on erosion rate. 
shared a decreasing trend at the pipe bending angle. Lower bending angle provided a narrow travel path to the multi-phase slurry flow, which raised flow irregularity. The highly disordered multi-phase flow striking through the pipe would remove a significantly larger proportion of the material from the pipe wall than that of pipe bends with a higher angle.

Figure 6 represents the erosive wear contours on the wall of different pipe bends at a velocity of $4 \mathrm{~m} / \mathrm{s}$. It is quite clear from the figure that the $30^{\circ}$ bend was eroded to a greater degree than the higher angle bend ( $90^{\circ}$ bend). For the lower angle bend, the erosion was observed over the complete bend curvature; however, a shift in the erosion location was identified when the bend angle increased and the wear location became limited only to the upper curvature for the $90^{\circ}$ bend. Thus, a higher bend angle $\left(90^{\circ}\right)$ significantly reduced the risk of erosive wear; therefore, it was more suitably applied to connecting different pipes of the slurry transport unit.

\subsection{Effect of pipe diameter on erosion rate}

The selection of an optimum pipe diameter for a slurry pipeline depends on several aspects such as allowable pressure drop, particulate concentration, size, etc. However, the pipeline diameter of a slurry transport unit should also be selected in terms of the least wear as the wear rate has strong dependency on the pipe diameter. To evaluate the effect of pipeline diameter on the erosive wear rate, simulations of pipe bends of different diameters ( $50 \mathrm{~mm}$ to $250 \mathrm{~mm}$ ) at different velocities ( 2 and $8 \mathrm{~m} / \mathrm{s}$ ) for $10 \%$ concentration of bottom ash particles (150 $\mu \mathrm{m}$ in diameter) were conducted. The variation in erosion rate and its relationship with the pipe diameter are shown in Figure 7. The inverse relationship between erosion rate and pipe diameter was found. A sharp decrement in the erosive wear was observed with increase in diameter of the pipe. The magnitude of maximum erosion was reduced by approximately 11 times when the pipe diameter

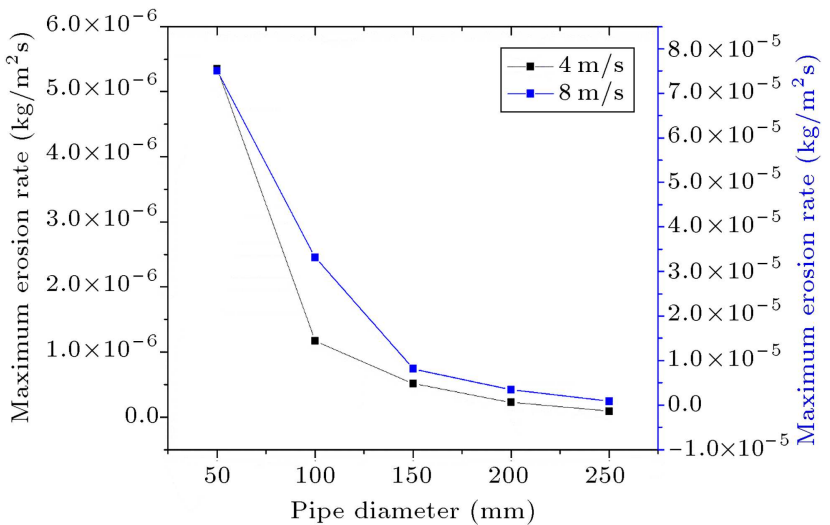

Figure 7. Effect of pipe diameter on erosion rate.

changed from 50 to $250 \mathrm{~mm}$, which could also be seen from the erosion contours shown in Figure 8. Of note, further enlargement of pipe diameter beyond $200 \mathrm{~mm}$ caused less variation in erosion rate and the decreasing trend tended to stabilize. Similar trends were observed by Peng and Cao [15].

The primary reason for such behavior is that the turbulence of a shorter diameter pipe becomes highly intense near the wall which helps the particles gain extra momentum and thus, it strikes the wall with great impact and results in severe erosion, as shown in Figure 9. The larger pipes (200-250 mm diameter) are of stronger turbulence intensity away from the pipe wall, which results in lower erosion of such pipelines.

Another possible cause of variation in erosive wear characteristics is the change in the flow path of the multi-phase regime, as shown in Figure 10. For the smaller diameter pipe, the multi-phase slurry flow travels through a narrow channel due to which the solid particles are deviated from the flowing stream and undergo numerous collisions with the inner wall. The multiple impacts of the solid particle removed significantly more amounts of material from the pipe wall; thus, the $50-\mathrm{mm}$ diameter pipe suffered more erosive wear than the 200 or $250 \mathrm{~mm}$ diameter pipe.

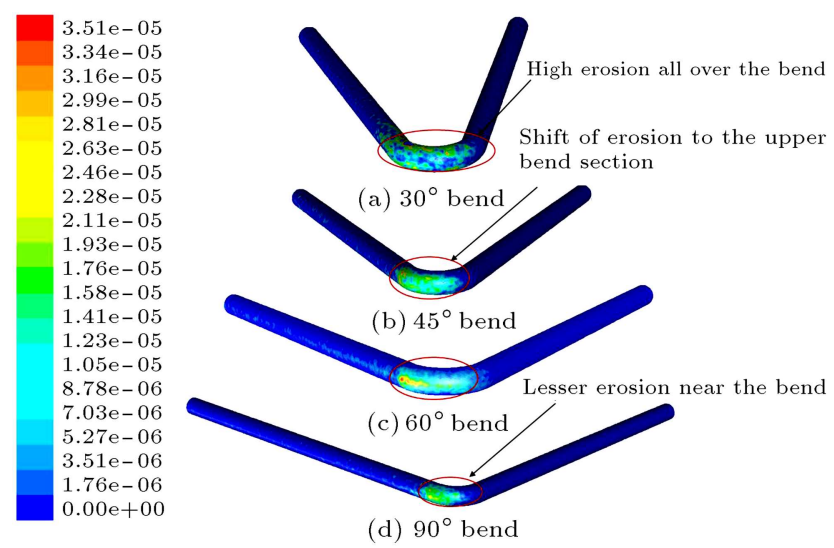

Figure 6. Contours of erosion $\left(\mathrm{kg} / \mathrm{m}^{2} \mathrm{~s}\right)$ at pipe wall for $4 \mathrm{~m} / \mathrm{s}$ velocity. 

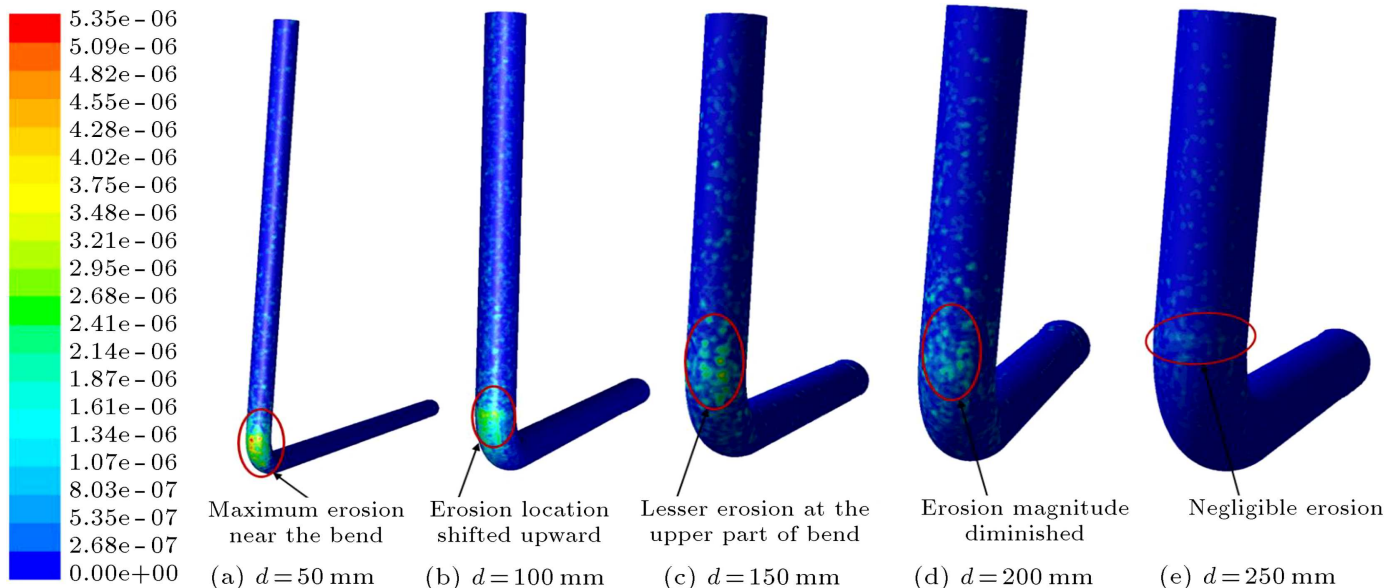
(a) $d=50 \mathrm{~mm}$
(b) $d=100 \mathrm{~mm}$
(c) $d=150 \mathrm{~mm}$

(d) $d=200 \mathrm{~mm}$

(e) $d=250 \mathrm{~mm}$

Figure 8. Contours of erosion rate on different diameter pipes.

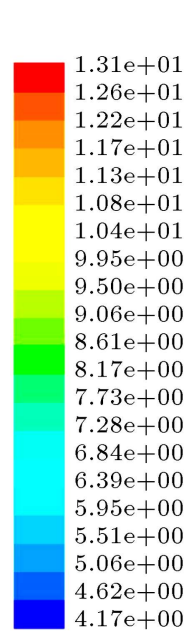

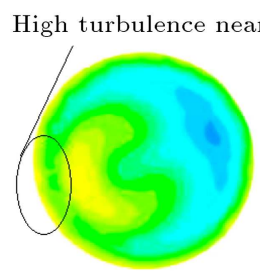

(a) $50 \mathrm{~mm}$ diameter

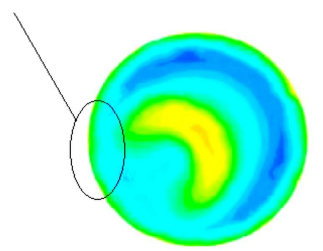

(b) $100 \mathrm{~mm}$ diameter

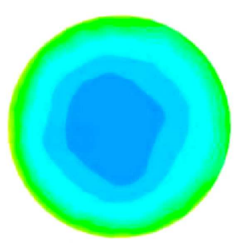

(c) $150 \mathrm{~mm}$ diameter

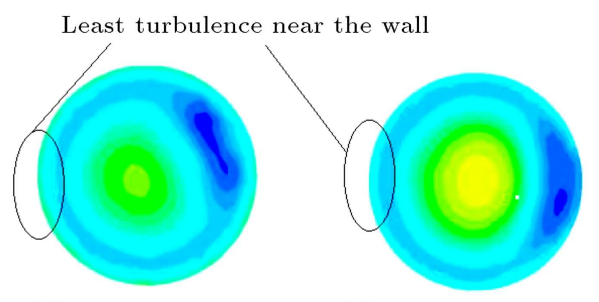

(d) $200 \mathrm{~mm}$ diameter

(e) $250 \mathrm{~mm}$ diameter

Figure 9. Turbulent intensity contours at the outlet of different diameter bends at $4 \mathrm{~m} / \mathrm{s}$.

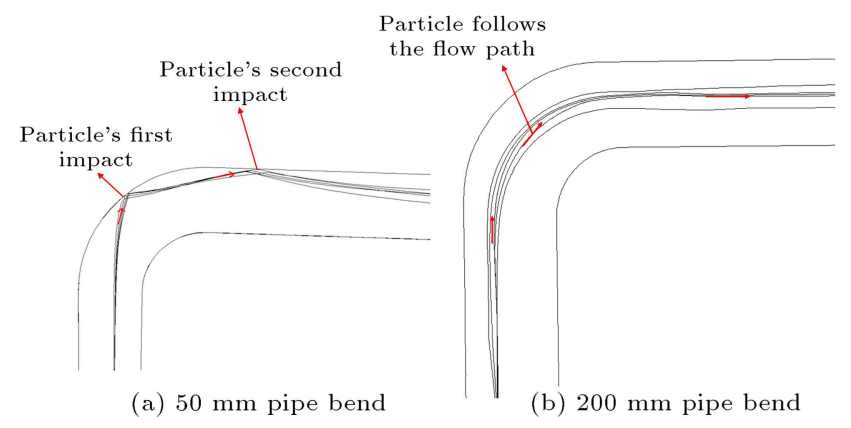

Figure 10. Particle tracks for different pipe bend.

\subsection{Effect of flow velocity}

In this section, the erosion wear characteristics of two larger diameter pipes (150 and $250 \mathrm{~mm}$ ) having a $90^{\circ}$ bend curvature are evaluated at different slurry flow velocities, as plotted in Figure 11. It was found that erosion rate grew exponentially with an increase in velocity. The magnitude of erosion of the $250 \mathrm{~mm}$ diameter pipe was $4.4 \times 10^{-7} \mathrm{~kg} / \mathrm{m}^{2} \mathrm{~s}$ at a velocity of
$8 \mathrm{~m} / \mathrm{s}$, while it was reduced to $3.31 \times 10^{-9} \mathrm{~kg} / \mathrm{m}^{2} \mathrm{~s}$ at a velocity of $2 \mathrm{~m} / \mathrm{s}$. The effect of velocity on erosion rate was the most significant of all the other parameters. The erosion rate of the $150-\mathrm{mm}$ diameter pipe bend increased by approximately 2.5 times when the flow velocity increased from 2 to $4 \mathrm{~m} / \mathrm{s}$. However, erosion wear in the pipeline was found negligible at velocities lower than $2 \mathrm{~m} / \mathrm{s}$, although at higher velocities, the impact energy of the flow was much higher and thus, the particles hit the wall with tremendous force that resulted in severe erosion, as in cases of Badr et al. [7] and Habib et al. [33].

\subsection{Effect of radius-to-diameter $(r / D)$ ratio}

The ratio of bend radius to pipe diameter of a slurry pipeline may significantly reduce the erosion wear caused by particulate impingement. Several pipes of different radius-to-diameter ratios $(r / D=1,1.5$, 2 , and 2.5), each of which was characterized by a diameter of $100 \mathrm{~mm}$, were simulated to determine 


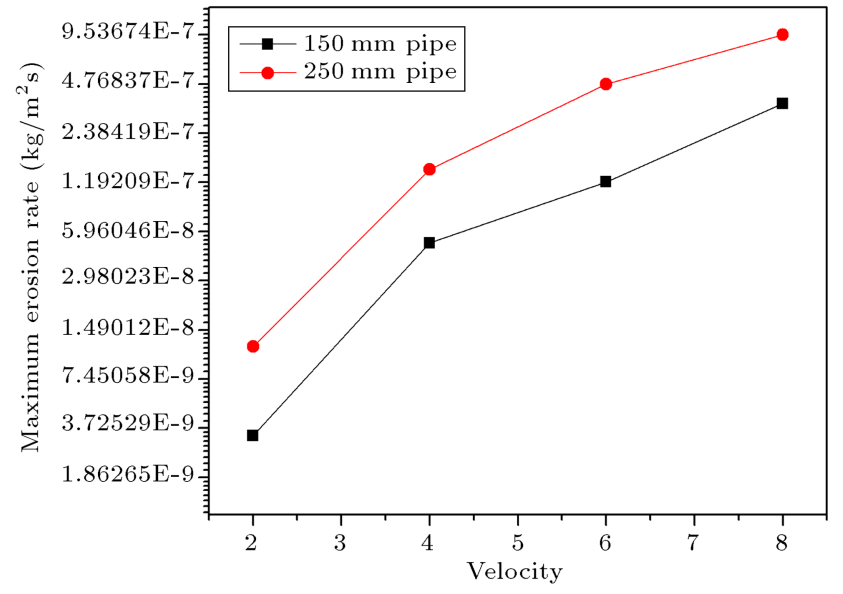

Figure 11. Effect of velocity on erosion rate.

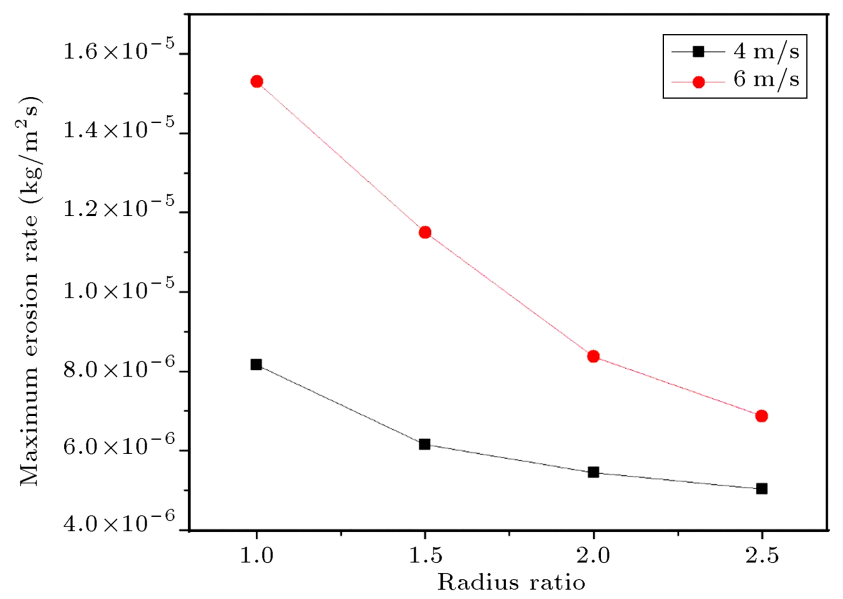

Figure 12. Variation in erosion rate for different $r / D$ ratio pipes.

the least erosion-affected configuration. Figure 12 illustrates the effect of $r / D$ ratio of pipe bend on the erosion wear rate at different velocities. It was found that the erosion rate significantly reduced with an increase in the $r / D$ ratio. An approximate $53 \%$ reduction in erosion rate was identified when the $r / D$ ratio increased from 1 to 2.5 at a flow velocity of 6 $\mathrm{m} / \mathrm{s}$ and a solid concentration of $10 \%$.

The contours of erosion at the wall of different $r / D$ ratio pipes are shown in Figure 13. Very low wear of the pipe with a higher $r / D$ ratio was observed. The larger value of $r / D$ made the bend curvature longer due to which the erodent would flow more steadily and cause less collision with the pipe wall. Thus, the slurry pipe bend must have a higher $r / D$ ratio to reduce the magnitude of erosion wear.

\section{Conclusion}

In this work, a simulation study was carried out using commercial CFD code FLUENT 15.0 to propose the least erosion-affected design slurry pipeline. The erosion wear for the complex bottom ash slurry flow was evaluated for different geometrical pipes in different operating conditions. The following conclusions can be drawn from the present study:

- The erosion wear rate of the larger angle bend $\left(90^{\circ}\right.$ bend) was found to be 4 times lower than that of the $30^{\circ}$ pipe bend at the same flow velocity and particulate concentration; thus, the higher bend angle was more suitable for connecting slurry pipelines.

- The erosion wear rate had an inverse relationship with the pipeline diameter. The larger diameter pipe $(150 \mathrm{~mm})$ suffered an erosion rate 6 times lower than the smaller diameter pipe $(50 \mathrm{~mm})$; therefore, the pipeline having a diameter of 150 $\mathrm{mm}$ or above was the highly suitable for a slurry transport unit.

- The bending radius had low, yet significant, effect on erosion rate. Approximately a 53\% reduction in the erosion wear rate could be achieved by installing pipe bends with a higher bend radius to diameter ratio $(r / D=2.5)$. The fluid flow in the

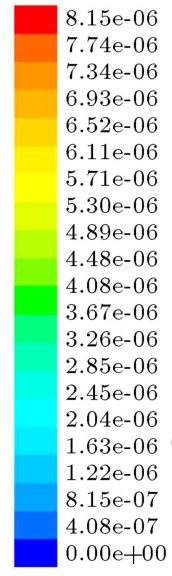

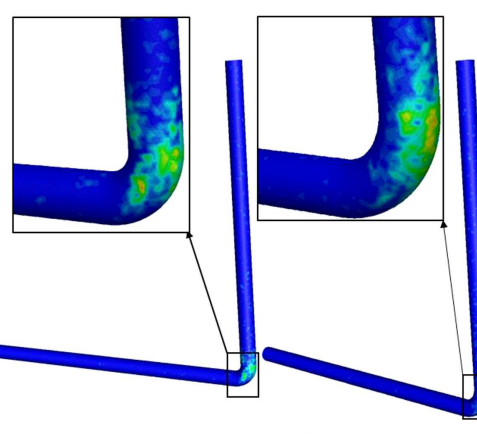

(a) $r / D=1$

(b) $r / D=1.5$

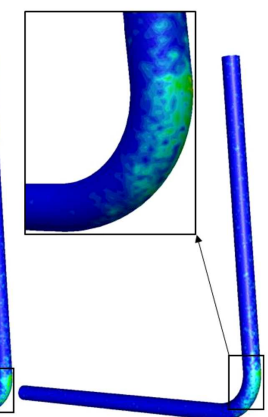

(d) $r / D=2.5$

Figure 13. Erosion contours at the wall of different $r / D$ ratio pipes. 
larger radius bend seems to be more similar to the flow in the straight pipe.

- Therefore, an optimal slurry pipeline must have a larger pipe diameter $(\geq 150 \mathrm{~mm})$ and be connected to the bends having a higher bend angle $\left(90^{\circ}\right.$ bend) and a larger $r / D$ ratio $(r / D \geq 2)$.

\section{Nomenclature}

$A \quad$ Cross-section area of pipe, $\mathrm{m}^{2}$

$D \quad$ Pipe diameter, $\mathrm{m}$

$F_{b} \quad$ Buoyancy force, $\mathrm{N}$

$F_{d} \quad$ Fluid drag force, $\mathrm{N}$

$F_{g} \quad$ Gravitational force, $\mathrm{N}$

$g \quad$ Acceleration due to gravity, $\mathrm{ms}^{-2}$

$d_{p} \quad$ Particle diameter, $\mathrm{m}$

$m_{p} \quad$ Particle mass, $\mathrm{m}$

$n \quad$ Exponent

$P \quad$ Pressure, $\mathrm{Pa}$

$T \quad$ Time, s

Re Reynolds number

$K \quad$ Turbulence kinetic energy, $\mathrm{m}^{2} \mathrm{~s}^{-2}$

$V_{f} \quad$ Particle Relative velocity, $\mathrm{ms}^{-1}$

$U_{P} \quad$ Particle velocity, $\mathrm{ms}^{-1}$

\section{References}

1. Modi, O.P., Dasgupta, R., Prasad, B.K., Jha, A.K., Yegneswaran, A.H., and Dixit, G. "Erosion of a highcarbon steel in coal and bottom-ash slurries", J. Mater. and Eng Perform., 9, pp. 522-529 (2000).

2. Shah, S.R., Rastogi, S., and Mathis, O. "Application of dry bottom ash removal and transportation for utilization", Fly Ash Utilization Programme (FAUP), TIFAC, DST, New Delhi, India (2005).

3. Behera, S., Sahu, A.K., Das, S., Senapati, P.K., and Mishra, S.K. "Scale-up design and erosion studies of bottom ash in pneumatic conveying system", Coal Combustion and Gasification Products, 5, pp. 1-8 (2013).

4. Brown G.J. "Erosion prediction in slurry pipeline tee-junctions", Appl. Math. Model., 26, pp. 155-170 (2002).

5. Zhu, M., Sun, L., Ou, G., Wang, K., Wang, K., and Sun, Y. "Erosion corrosion failure analysis of the elbow in sour water stripper overhead condensing reflux system", Eng. Fail. Anal., 62, pp. 93-102 (2012).

6. Njobuenwu, D.O. and Fairweather, M. "Modelling of pipe bend erosion by dilute particle suspensions", Comput. Chem. Eng., 4, pp. 235-247 (2012).
7. Badr, H.M. and Habib, M.A. "Effect of flow velocity and particle size on erosion in a pipe with sudden contraction", The 6th Saudi Engineering Conference, KFUPM, Dhahran, December 5, pp. 79-95 (2002).

8. Wee, S.K. and Yap, Y.J. "CFD study of sand erosion in pipeline", J. Petrol. Sci. Eng., 176, pp. 269-278 (2019).

9. Kannojiya, V., Kumar, S., Kanwar, M., and Mohapatra, S.K. "Simulation of erosion wear in slurry pipe line using CFD", Appl. Mech. Mate., 852, pp. 459-465 (2016).

10. Kannojiya, V., Deshwal, M., and Deshwal, D. "Numerical analysis of solid particle erosion in pipe elbow", Mater. Today. Proc., 5, pp. 5021-5030 (2018).

11. Bernardo, S., Mori, M., Peres, A.P., and Isio Dion, R.P. "3-D computational fluid dynamics for gas and gas-particle flows in a cyclone with different inlet section angles", Powder Technol., 162, pp. 190-200 (2006).

12. Borkowski, P. and Sienicki, A. "Contacts erosion modelling using ansys computer software and experimental research", Arch. Metall. Mater., 60(2), pp. 551-560 (2015).

13. Zhang, P., Roberts, R.M., and Benard, A. "Computational guidelines and an empirical model for particle deposition in curved pipes using an EulerianLagrangian approach", J. Aerosol Sci., 53, pp. 1-20 (2012).

14. Zahedi, P., Karimi, S., Mahdavi, M., et al. "Parametric analysis of erosion in 90 degree and long radius bends", ASME Proceeding, Fluids Engineering Division Summer Meeting, FEDSM2016-7735P (2016).

15. Peng, W. and Cao, X. "Numerical prediction of solid particle erosion in pipe bends with liquid-solid flow", Powder Technol., 294, pp. 266-279 (2016).

16. Tu, J.Y., Fletcher, C.A.J., Behnia, M., Reizes, J.A., Owens, D., and Zones, P. "Prediction of flow and erosion in power utility boilers and comparison with measurement", J. Eng. Gas. Turb Power, 119(3), pp. 709-716 (1999).

17. Lee, B.E., Fletcher, C.A.J., and Behnia, M.J. "Computational prediction of tube erosion in coal fired power utility boilers", J. Eng. Gas. Turb. Power, 121(4), pp. 746-750 (1999).

18. Huttunen-Saarivirtaa, E., Kinnunen, H., Tuiremo, J., Uusitalo, M., and Antonov, M. "Erosive wear of boiler steels by sand and ash", Wear, 317, pp. 213-224 (2014).

19. Goosen, P. and Malgas, I. "An experimental investigation into aspects of wear in boiler ash disposal pipelines", 14th Int Conf Slurry Handel Pipeline Transp., pp. 8-10 (1999).

20. Das, S.K., Godiwalla, K.M., Mehrotra, S.P., Sastry, K.K.M., and Dey, P.K. "Analytical model for erosion behaviour of impacted fly-ash particles on coal-fired boiler components", Sadhana, 31(5), pp. 583-595 (2006). 
21. Singh, G., Kumar, S., and Mohapatra, S.K. "Erosion wear in a slurry pipe with multisized coal and bottomash slurries", Mater. Today Proc., 4, pp. 3565-3571 (2017).

22. Singh, J., Kumar, S., Singh, J.P., Kumar, P., and Mohapatra, S.K. "CFD modeling of erosion wear in pipe bend for the flow of bottom ash suspension", Particul. Sci. Technol., 37(3), pp. 275-285 (2019). https://doi.org/10.1080/02726351.2017.1364816.

23. Kannojiya, V., Darshan, M.B., and Chandra, Y.P. "Numerical analysis of erosion wear and pressure drop for turbulent multiphase slurry flow", Arch, Mech. Eng., 65(3), pp. 361-378 (2018).

24. Fluent, I. "Fluent 6.3 user guide", Fluent Inc., Lebanon (2002).

25. Morsi, S.A. and Alexander, A.J. "An investigation of particle trajectories in two-phase flow systems", $J$ Fluid Mech., 52(2), pp. 193-208 (1972).

26. Edwards, J.K. "Development, validation, and application of a three dimension, CFD-based erosion prediction procedure", Ph.D. Thesis, The University of Tulsa, Tulsa (2000).

27. Safaei, M.R., Mahian, O., Garoosi, F., Hooman, K., Karimipour, A., Kazi, S.N., and Gharehkhani, S. "Investigation of micro- and nanosized particle erosion in a $90^{\circ}$ pipe bend using a two-phase discrete phase model", Sci. World J., 2014, Article ID 740578, 12 pages (2014). http://dx.doi.org/10.1155/2014/740578.

28. Campos-Amezcua, A., Gallegos-Muñoz, A., Alejandro Romero, C., Mazur-Czerwiec, Z., and CamposAmezcua, R. "Numerical investigation of the solid particle erosion rate in a steam turbine nozzle", Appl. Therm. Engi., 27, pp. 2394-2403 (2007).
29. Kamarudin, N.H., Prasada Rao, A.K., and Azhari, A. "CFD based erosion modelling of abrasive waterjet nozzle using discrete phase method", IOP Conf. Series: Materials Science and Engineering, 114, pp. 1-8 (2016).

30. Bozzini, B., Ricotti, M.E., Boniardi, M., and Mele, C. "Evaluation of erosion-corrosion in multiphase flow via CFD and experimental analysis", Wear, 255, pp. 237-45 (2003). DOI:10.1016/s0043-1648(03)00181-9.

31. Cotton, K.C., Evaluating and Improving Steam Turbine Performance, Cotton Fact Inc., New York (1993).

32. Shamshirband, S., Malvandi, A., Karimipour, A., et al. "Performance investigation of micro- and nano-sized particle erosion in a $90^{\circ}$ elbow using an ANFIS model", Powder Technol., 284, pp. 336-343 (2015).

33. Habib, M.A., Badr, H.M., and Kabir, M.E. "Erosion and penetration rates of a pipe protruded in a sudden contraction", Compt. Fluids., 37, pp. 146-160 (2008).

\section{Biographies}

Vikas Kannojiya is a Research Scholar in the Mechanical and Industrial Engineering Department, IIT Roorkee, India. His research focuses on computational fluid dynamics, erosion wear, bio-fluidics and medical device design.

Satish Kumar is an Associate Professor in the Mechanical Engineering Department, Thapar University, India. His research interest focuses on rheology of solid-liquid suspension, erosion wear, CFD, solid-liquid flow. 